\title{
Elite Techniques in Shoulder Arthroscopy
}



John D. Kelly IV

Editors

Elite Techniques

in Shoulder Arthroscopy

New Frontiers in Shoulder Preservation

量 Springer 


\section{Editor}

John D. Kelly IV, MD

Director, Shoulder Sports Medicine

Director, Penn Center for Throwing Athletes

University of Pennsylvania

Department of Orthopedics

Philadelphia, PA, USA

ISBN 978-3-319-25101-1

ISBN 978-3-319-25103-5 (eBook)

DOI 10.1007/978-3-319-25103-5

Library of Congress Control Number: 2015958660

Springer Cham Heidelberg New York Dordrecht London

(C) Springer International Publishing Switzerland 2016

This work is subject to copyright. All rights are reserved by the Publisher, whether the whole or part of the material is concerned, specifically the rights of translation, reprinting, reuse of illustrations, recitation, broadcasting, reproduction on microfilms or in any other physical way, and transmission or information storage and retrieval, electronic adaptation, computer software, or by similar or dissimilar methodology now known or hereafter developed.

The use of general descriptive names, registered names, trademarks, service marks, etc. in this publication does not imply, even in the absence of a specific statement, that such names are exempt from the relevant protective laws and regulations and therefore free for general use.

The publisher, the authors and the editors are safe to assume that the advice and information in this book are believed to be true and accurate at the date of publication. Neither the publisher nor the authors or the editors give a warranty, express or implied, with respect to the material contained herein or for any errors or omissions that may have been made.

Printed on acid-free paper

Springer International Publishing AG Switzerland is part of Springer Science+Business Media (www.springer.com) 
I dedicate this book to my family.

To my daughters, Mary Elizabeth and Ann Marie: I thank God for you daily. I could not have "scripted" better daughters. You both exude kindness, compassion, and dignity. You both will truly effect meaningful change in your lifetimes.

To Marie, the love of my life, the answers to my prayers: You are the greatest exemplar of compassion I have known. You continually provide me with wise counsel, unwavering loyalty, and steadfast support.

You will always be my soul mate. 



\section{Foreword}

One of the big challenges in teaching shoulder arthroscopy today is that many of the techniques are so sophisticated that the craftsmanship necessary to perform these procedures can be difficult to convey. Yet the burden of craft that is incumbent upon arthroscopic shoulder surgeons is greater than ever.

Dr. John D. Kelly IV has assembled a formidable group of authors to elucidate the fine points of Elite Techniques in Shoulder Arthroscopy, incorporating the title of his book into the mission of this important work. However, the subtitle of his book, New Frontiers in Shoulder Preservation, is equally a statement of this mission. In my opinion, shoulder arthroscopy is the single greatest tool that the orthopedic surgeon can implement toward the goal of joint preservation for any joint in the body. And joint preservation is particularly important in this day of conflicting expert opinions in which the surgeon may be confused as to whether to treat a large or massive rotator cuff tear with arthroscopic repair (joint preserving) or reverse total shoulder replacement (joint sacrificing).

John Kelly has been my friend for more than 15 years, and I have always admired his determination to do the right thing for his patients. He does the right thing whether or not it is easy. And as my fellows have often heard me say, "There's the easy way and there's the cowboy way." I am glad to confirm that Dr. Kelly is preserving and advancing the "cowboy way" of shoulder arthroscopy with his excellent new book. Strong work!

San Antonio, TX

Stephen S. Burkhart, MD

June 28, 2015 



\section{Preface}

This book is a mere reflection of the graces and blessings I have received from my teachers, mentors, and those involved in my formation.

I wish to acknowledge the sage teachers who enriched my ability to provide ethical and up-to-date care of my patients.

John Lachman taught me the ethics of patient care like no other. Ray Moyer was the greatest exemplar of integrity and loving patient care I have ever known. Joseph Torg is perhaps the wisest counselor on matters of life and orthopedics on earth.

Steven Burkhart taught me how to view a shoulder in mechanical terms, while Felix "Buddy" Savoie continues to instruct me in the most revolutionary shoulder arthroscopic techniques.

I have had the "gift" of a tried and true friend and colleague, Brian Sennett, who has been a continual supportive force in my career, in addition to a superlative source of shoulder knowledge.

My chairman, L. Scott Levin, has supported my academic endeavors without question and has proven time and time again that leadership is all about "walking the talk."

Finally, I wish to acknowledge my editor, Jenn Schneider, who demonstrated the "patience of Job" in seeing this work to completion.

Philadelphia, PA

John D. Kelly IV, MD 



\section{Contents}

\section{Part I Overhead Athlete}

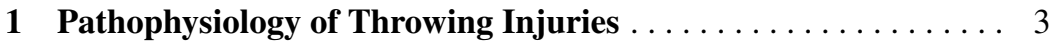
Stephen J. Thomas, W. Ben Kibler, and Aaron Sciascia

2 Prevention of Labral and Rotator Cuff Injuries in the Overhead Athlete . . . . . . . . . . . . . . . . . . . . 25 Nathan W. Skelley and Matthew V. Smith

3 Keys to Successful Labral Repair 35 Dinesh Dhanaraj, Nicole S. Belkin, Miltiadis H. Zgonis, and Brian J. Sennett

4 Indications and Technique for Posterior Capsule Release .... . 45 John G. Horneff III, G. Russell Huffman, and John D. Kelly IV

5 Throwing Acquired Anterior Rotator Interval Pathology . . . . 53 Craig D. Morgan and Kevin J. McHale

\section{Part II Instability}

6 Evaluation of Bone Loss and the Glenoid Track . . . . . . . . . . 67 Nancy A. Chauvin, Vishal Saxena, Stuart D. Kinsella, and Jose M. Morey

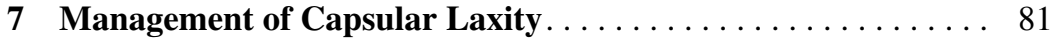
C. Edward Hoffler II, Fotios P. Tjoumakaris, and Luke Austin

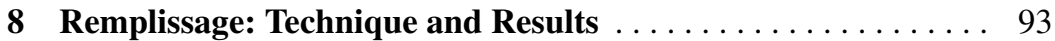
Christos D. Photopoulos, Min Jung Park, and John D. Kelly IV

9 Arthroscopic Latarjet. . . . . . . . . . . . . . . . . . . 101 Sohale Sadeghpour, Michael J. O’Brien, and Felix H. Savoie III

10 Posterior Instability

Pramod B. Voleti, Fotios P. Tjoumakaris, Brian J. Sennett, and James P. Bradley 


\section{Part III Glenohumeral Arthritis}

11 Pearls for Thorough Debridement, Capsular Release,

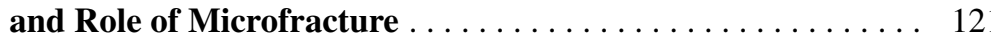

Brian C. Domby, Brian J. Cole, and Eric C. McCarty

12 The Comprehensive Arthroscopic Management

(CAM) Procedure for Young Patients

with Glenohumeral Osteoarthritis

Peter J. Millett, Joshua A. Greenspoon, and Ryan J. Warth

13 Graft Interposition Arthroplasty

Michael J. O'Brien and Felix H. Savoie III

14 Adhesive Capsulitis: Diagnosis, Etiology, and Treatment Strategies

Joshua Asher Gordon, Eric Breitbart, Daniel C. Austin,

Christos D. Photopoulos, and John D. Kelly IV

Part IV Rotator Cuff

15 Ultrasound in Rotator Cuff Evaluation

Christos D. Photopoulos, Ann Marie Kelly, and Viviane Khoury

16 Indications for Repair: Who Really Needs Surgery? . . . . . . 181 Robert W. Westermann and Brian R. Wolf

17 Biologic Augmentation of Rotator Cuff Repair

Jon-Michael E. Caldwell, Xinzhi Zhang, Helen H. Lu, and William N. Levine

18 Indications and Techniques for Double-Row Fixation

Lauren Wessel, Joshua Sykes, Jason B. Anari, and David Glaser

19 Retracted Subscapularis Tears

Patrick J. Denard and Stephen S. Burkhart

20 Arthroscopic Repair of Massive Retracted

Rotator Cuff Tears

Michael H. McGraw, Stuart D. Kinsella, Ann Marie Kelly,

and John D. Kelly IV

21 The Use of Graft Augmentation in the Treatment of Massive Rotator Cuff Tears

Barbara Steele, Joshua Asher Gordon, and Marc Labbé

22 Suprascapular Nerve Release: General Principles

Arash A. Dini, Michael J. O’Brien, and Felix H. Savoie III

23 Distal Suprascapular Nerve Compression:

Spinoglenoid Ligament Release.

Kevin D. Plancher and Stephanie C. Petterson 


\section{Part V Post Op Care}

24 Maximizing Return to Activity Post Cuff and Instability Surgery.

Marisa Pontillo and Brian Leggin

25 When Is the Patient Truly "Ready to Return,"

a.k.a. Kinetic Chain Homeostasis

Aaron Sciascia and Michele Monaco

Index. 



\section{Contributors}

Jason B. Anari, MD Department of Orthopaedic Surgery, University of Pennsylvania, Philadelphia, PA, USA

Daniel C. Austin, MD Department of Orthopaedic Surgery, Dartmouth Hitchcock Medical Center, Lebanon, NH, USA

Luke Austin, MD Department of Orthopaedic Surgery, Thomas Jefferson University Hospital, Sewell, NJ, USA

Nicole S. Belkin, MD Department of Orthopaedic Surgery, Hospital of the University of Pennsylvania, Philadelphia, PA, USA

James P. Bradley, MD Department of Orthopaedic Surgery, University of Pittsburgh School of Medicine, Pittsburgh, PA, USA

Eric Breitbart, MD Department of Orthopaedic Surgery, University of Pennsylvania Health Systems, Philadelphia, PA, USA

Stephen S. Burkhart, MD The San Antonio Orthopaedic Group, San Antonio, TX, USA

Jon-Michael E. Caldwell, MD Department of Orthopaedic Surgery, New York Presbyterian-Columbia University Medical Center, New York, NY, USA

Nancy A. Chauvin, MD Department of Radiology, The Children's Hospital of Philadelphia, Philadelphia, PA, USA

Perelman School of Medicine at the University of Pennsylvania, Philadelphia, PA, USA

Brian J. Cole, MD, MBA Department of Orthopaedics, Rush University Medical Center, Chicago, IL, USA

Patrick J. Denard, MD Southern Oregon Orthopedics, Medford, OR, USA

Dinesh Dhanaraj, MD, MSPH Department of Orthopaedic Surgery, Princeton HealthCare System, Plainsboro, NJ, USA

Arash A. Dini, MD Department of Orthopaedics, Tulane University School of Medicine, New Orleans, LA, USA

Brian C. Domby, MD Orthopaedic Sports Medicine and Spine Center, Florida Medical Clinic, Tampa, FL, USA 
David Glaser, MD Department of Orthopaedic Surgery, University of Pennsylvania, Philadelphia, PA, USA

Joshua Asher Gordon, MD Department of Orthopaedic Surgery, Hospital of the University of Pennsylvania, Philadelphia, PA, USA

Joshua A. Greenspoon, BSc Vail Valley Medical Center, Steadman Philippon Research Institute, Vail, CO, USA

C. Edward Hoffler II, PhD, MD The Miami Hand and Upper Extremity Institute, Miami, FL, USA

John G. Horneff III, MD Rothman Institute Orthopaedics, Thomas Jefferson University, Philadelphia, PA, USA

G. Russell Huffman, MD, MPH Department of Orthopaedic Surgery, University of Pennsylvania, Philadelphia, PA, USA

Ann Marie Kelly, BA Department of Orthopedics, University of Pennsylvania, Philadelphia, PA, USA

John D. Kelly IV, MD Department of Orthopaedics, University of Pennsylvania, Philadelphia, PA, USA

Viviane Khoury, BSc, MD Division of Musculoskeletal Imaging, University of Pennsylvania Health System, Philadelphia, PA, USA

W. Ben Kibler, MD Lexington Clinic, Shoulder Center of Kentucky, Lexington, KY, USA

Stuart D. Kinsella, MD, MTR Department of Orthopaedic Surgery, Massachusetts General Hospital, Boston, MA, USA

Marc Labbé, MD Department of Orthopaedic Surgery, Baylor College of Medicine, Houston, TX, USA

University of Texas Medical Branch, Galveston, TX, USA

Brian Leggin, PT, DPT, OCS Penn Therapy and Fitness at Valley Forge, Berwyn, PA, USA

William N. Levine, MD Department of Orthopaedic Surgery, New York Presbyterian-Columbia University Medical Center, New York, NY, USA

Helen H. Lu, PhD Department of Biomedical Engineering, Columbia University, New York, NY, USA

Eric C. McCarty, MD Department of Orthopaedic Surgery, University of Colorado School of Medicine, Aurora, CO, USA

Michael H. McGraw, MD Department of Orthopaedic Surgery, Hospital of the University of Pennsylvania, Philadelphia, PA, USA

Kevin J. McHale, MD Department of Orthopaedic Surgery, Hospital of the University of Pennsylvania, Philadelphia, PA, USA

Peter J. Millett, MD, MSc Vail Valley Medical Center, The Steadman Clinic, Vail, CO, USA 
Michele Monaco, DSc, ATC Department of Human Movement Science, Immaculata University, Immaculata, PA, USA

Jose M. Morey, MD Department of Radiology and Biomedical Imaging, University of Virginia, Hampton, VA, USA

Department of Internal Medicine, Eastern Virginia Medical School, Hampton, VA, USA

Department of Radiology, Hampton VA Medical Center, Hampton, VA, USA Almaden Research Lab, IBM Watson, Hampton, VA, USA

Craig D. Morgan, MD Morgan Kalman Clinic, Wilmington, DE, USA

Michael J. O'Brien, MD Department of Orthopaedics, Tulane University School of Medicine, New Orleans, LA, USA

Min Jung Park, MD, MMSc Department of Orthopaedic Surgery, Southern California Permanente Medical Group, Lancaster, CA, USA

Stephanie C. Petterson, MPT, PhD Orthopaedic Foundation, Stamford, CT, USA

Christos D. Photopoulos, MD Department of Orthopaedic Surgery, Hospital of the University of Pennsylvania, Philadelphia, PA, USA

Kevin D. Plancher, MD, MS Clinical Professor, Department of Orthopaedic Surgery, Albert Einstein College of Medicine, New York, NY, USA

Marisa Pontillo, PT, DPT, SCS GSPP Penn Therapy and Fitness, Penn Sports Medicine Center, Philadelphia, PA, USA

Sohale Sadeghpour, MD Department of Orthopaedics, Tulane University School of Medicine, New Orleans, LA, USA

Felix H. Savoie III, MD Department of Orthopaedics, Tulane University School of Medicine, New Orleans, LA, USA

Vishal Saxena, MD Department of Orthopaedic Surgery, University of Pennsylvania, Philadelphia, PA, USA

Aaron Sciascia, MS, ATC, PES Lexington Clinic, Should Center of Kentucky, Lexington, KY, USA

Brian J. Sennett, MD Department of Orthopaedic Surgery, University of Pennsylvania, Philadelphia, PA, USA

Penn Sports Medicine Center, Philadelphia, PA, USA

Nathan W. Skelley, MD Department of Orthopaedic Surgery, BarnesJewish Hospital/Washington University in St. Louis, Saint Louis, MO, USA

Matthew V. Smith, MD, MSc Department of Orthopaedics, Washington University in St. Louis, Saint Louis, MO, USA

Barbara Steele, MD Orthopaedic Surgery Sports Medicine, University of Pennsylvania Health System, Philadelphia, PA, USA 
Joshua Sykes, MD Department of Orthopaedic Surgery, University of Pennsylvania, Philadelphia, PA, USA

Stephen J. Thomas, PhD, ATC Department of Kinesiology, Temple University, Philadelphia, PA, USA

Fotios P. Tjoumakaris, MD Department of Orthopaedic Surgery, The Rothman Institute, Thomas Jefferson University Hospital, Egg Harbor Township, NJ, USA

Pramod B. Voleti, MD Department of Orthopaedic Surgery, Hospital of the University of Pennsylvania, Philadelphia, PA, USA

Ryan J. Warth, MD Department of Orthopaedic Surgery, University of Texas Health Sciences Center, Houston, TX, USA

Lauren Wessel, BS Department of Orthopaedic Surgery, Washington University in St. Louis, Houston, TX, USA

Robert W. Westermann, MD Department of Orthopaedics and Rehabilitation, University of Iowa Hospitals and Clinics, Iowa City, IA, USA

Brian R. Wolf, MD, MS Department of Orthopaedics and Rehabilitation, University of Iowa Hospitals and Clinics, Iowa City, IA, USA

Miltiadis H. Zgonis, MD Department of Orthopaedic Surgery and Sports Medicine, University of Pennsylvania, Philadelphia, PA, USA

Penn Sports Medicine Center, Philadelphia, PA, USA

Xinzhi Zhang, PhD Department of Biomedical Engineering, Columbia University, New York, NY, USA 